\title{
Research on the Cultivation of College English Autonomous Learning Ability
}

\section{Zhuofu Sun}

Shenyang Aerospace University, Shenyang, Liaoning, 110136

\author{
Keywords: English Learning, Learning Method, Cultivation Strategy
}

\begin{abstract}
Cultivating students' self-learning ability has become an important goal of college English teaching reform in China in recent years. In view of the current situation of college English teaching and the misunderstanding of self-learning, combined with constructivism and autonomous learning theory, the independent learning and related elements are discussed. Cultivate the intrinsic elements of the learner and continuously build a language learning environment and resources can effectively cultivate learners' independent learning ability and improve English teaching.
\end{abstract}

\section{Introduction}

With the deep development of lifelong learning concepts and quality education, more and more researchers realize that independent learning is of great significance to improve learners' learning ability and effect. "College English Course Requirements" (2007) pointed out that the goal of college English teaching is to develop students' comprehensive English application ability and enhance students' self-learning ability. One of the purposes of the reform of teaching model is to promote the formation of individualized learning methods for students and the development of students' self-learning ability in English. Back to the reality, Chinese college English education has long been affected by CET-4 and CET- 6 and other students' self-learning is greatly restricted. The arrival of the information age and the popularity of the Internet have made it possible for students to obtain instant access to professional knowledge. Therefore, how to independently select learning materials suitable for their own cognitive level and achieve as much improvement as possible has become an urgent problem to be solved.

\section{Self-directed learning and its misunderstanding}

The autonomous learning model is based on the constructivist theory, emphasizing that the learner is the cognitive subject, the active constructor of the knowledge meaning, not the passive recipient of knowledge and the instilling object. Learning is not passively accepting information, but the process of actively constructing knowledge. It is the process by which learners process external information according to their own experience background to obtain their own meaning and understanding. The constructivist theory also points out that it is necessary to use the help of others in the learning process and make full use of various learning resources. In the field of language teaching, there is no uniform definition of autonomous learning so far. Many Chinese and foreign scholars have studied autonomous learning from different perspectives, and have produced different definitions, such as: self-regulated learning, active learning, self-planning learning, self-monitoring, self-controlled learning. Holec, who first started researching foreign language autonomous learning, believes that having autonomous learning ability means that learners have the ability to determine learning objectives, content, materials, methods, time and progress, and to evaluate learning [3]. Self-learning research authority Zimmerman believes that when students are active participants in metacognition, motivation, and behavior, their learning is autonomous [4]. Dickinson pointed out that self-directed learning refers to the ability to learn attitudes and learn independently. Learners can choose to use appropriate learning strategies and monitor learning strategies, and adjust if necessary to monitor the effects of learning [5]. Dam believes that learner autonomy depends not only on individuals but also on groups. Learners can only better acquire the ability to learn independently by working with others [6]. 
Although it can be defined from multiple angles, it is certain that autonomous learning is not "self-study". Autonomous learning can be divided into two types: complete self-learning and incomplete self-learning. The difference lies in whether learners choose and control all relevant aspects of autonomous learning. Complete self-directed learning is the ultimate goal of learning. If English learning at the university level suddenly becomes a full responsibility of the students from the full control of the teachers in the middle school stage, not only can the learning effect not be guaranteed, but also some students may be in trouble. College English teaching is in the initial stage of the cultivation of students' self-learning ability. The self-learning mode widely studied and explored at present is incomplete self-learning. The purpose is to gradually develop students' autonomy and help them master relevant knowledge and strategies. Self-directed learning is not an individual and isolated learning. The ultimate goal of language acquisition is to acquire the ability of oral and written communication. The social and communicative nature of language determines that English learning should be the process of interaction and cooperation. The negotiation, cooperation and mutual supervision between teachers and students and students are promoted in self-directed learning.

\section{Factors affecting the cultivation of college English autonomous learning ability}

Learner's learning concept. Although the education authorities have developed detailed teaching requirements for English teaching in primary, secondary and primary schools, there is only one ultimate goal in English teaching: progression. Therefore, many students think that what the teacher teaches is what I will learn; as for what to learn and how to learn is what teachers should consider. If the teacher does not ask for it, the student feels that there is no need or even should be involved. Passive learning strategies lead to learners' poor self-learning, not understanding their own learning and learning needs, and not knowing how to learn. They despise the "soft" assignments in class discussions and oral practice, and are reluctant to "waste time" to participate in student-centered academic and skill training, so that after learning English for many years, they still can't understand, can't speak, and can't write. The concept held by the learner will promote or hinder the development of autonomy. Therefore, it is necessary for teachers to understand and correct the students' self-learning concept before promoting learning autonomy [10]. To change the concept of learning, learners need to realize that they are the main body of learning. To learn English well, we must give full play to subjective initiative. Conscious learning requires learners to have the desire and needs of learning first, to clarify the purpose of learning, and to correct the attitude of learning. Second, learners need to understand their learning characteristics, improve their learning methods, and gradually approach and achieve the goals of self-learning, efficient learning, and happy learning. Finally, learners should also learn to think about learning, explore learning, improve learning, and form their own individual learning methods that are different from others.

Emotional Factors. Emotional factors are one of the biggest factors affecting autonomous learning, including learning motivation, learning interest and learning attitude. Experts and scholars in the foreign language teaching community generally believe that motivation is one of the main factors affecting the learning speed and effectiveness of second language learners. It provides learners with the main driving force for learning and encourages this long process to continue. From the perspective of educational psychology, learning motivation can be divided into deep motivation and superficial motivation. Surface motivation is the material stimulation of the surface, such as diplomas, good jobs, high wages, etc.; deep motivation is deep non-material stimulation, such as interest, curiosity, curiosity, etc. Those who rely solely on superficial motivation for learning, with the ultimate goal of obtaining material benefits, often adopt a passive coping style of learning strategies. They usually learn too much, and they even cheat when they pass the exam. Once they pass the exam, the learning activities will end. Learners lack initiative. Learners with deep motivation are voluntarily, pay attention to the learning process, and are more inclined to take the initiative to approach the learning task, and work hard and persevere. The survey shows that learners with deep learning motivation progress faster than those who rely on surface motivation . 


\section{College English Autonomous Learning Ability Development Path}

In the teaching process, the teacher should give way to the main body of the teaching, and play a scientific and reasonable guiding role in the English learning of the students. Teachers construct a task-based English learning system for students, which is embodied in the following processes: First, teachers should use the network or books before class according to the task of setting the teaching content of the class and the actual English level of the students. The library and other means to inquire about the content or materials related to it, so that students have a general understanding of the content of before class, understand the vocabulary used in the class, and lay a solid foundation for fully participating in the classroom teaching. Then, during the class, the teacher used the picture or video to brief the students on the content of the class. After the students were divided into several groups, they were asked to conduct group discussion and summary, and sent representatives to show the results of the discussion or determine the role to design the scenario. Performances allow students to provide a more lively and interesting classroom atmosphere, master the correct use of English vocabulary in laughter, and enhance the self-confidence of speaking English. Finally, the teacher will explain the difficulties of the class and make a reasonable evaluation of the students' achievements. The students can also evaluate each other or reflect on themselves. Task-based English learning can greatly stimulate students' enthusiasm and initiative, and become the main body of the classroom to carry out learning activities.

School leaders should fully recognize the importance of micro-courses for students' independent English learning, and establish a large-scale English self-learning platform for teachers and students to use in the school. It is also necessary to ensure that this platform is used efficiently. First of all, this platform must be timely. Teachers need to transfer the relevant micro-course video resources and a series of supplementary teaching resources to the platform before the class, so that students can preview the lessons before class. And use your mobile phone or computer to learn and review English knowledge at any time after class. Teachers can also supplement the knowledge points missing from this class on this platform. Secondly, this platform must be highly efficient. Platform administrators introduce a learning evaluation system on the platform to make objective and reasonable evaluations of students' performance on this platform and publicize the evaluation results. This evaluation system helps to create a competitive atmosphere among students and to stimulate students' enthusiasm and initiative.

First of all, this evaluation system is not only applicable to teachers to students, but also applies equally to the evaluation of students, students and students, and students themselves. The multi-evaluation system helps to constrain students' learning performance from multiple angles, stimulate students' enthusiasm for learning, and improve themselves better. Secondly, teachers' evaluation of students should not be limited to the presentation of group results. It should also be used for students' pre-study, classroom performance, group participation, after-school assignments, and after-school performance on English autonomous learning platforms. Aspects are systematically evaluated. Because students are largely influenced by teacher evaluations, teachers should pay as much attention as possible to the performance of each student in the class, making the evaluation more perfect and playing a positive role for the students. Many students do not carry other electronic devices such as computers due to family conditions and other reasons. They can only use computers from other students or use computers in school rooms. However, according to the survey results, most of the computers in the school are old desktop computers introduced many years ago, and the number is too small to meet the learning requirements of the school. Therefore, the school should introduce a large number of advanced electronic equipment for students to improve the campus learning infrastructure. Provide students with a good learning environment. Moreover, the micro-course is a web-based online video teaching resource, and the backward network equipment is not conducive to students' English learning.

\section{Conclusion}

The development of self-learning ability not only helps learners to successfully complete English 
learning tasks, but also is an indispensable and important skill for them to continuously learn and explore innovation. Whether teachers can actively cultivate and induce the inner elements of learners and continuously construct external factors of language learning has become the key to measuring the success or failure of teachers. Under the guidance of teachers, students need to combine adaptive learning and exploratory learning organically, and gradually complete the transition from "I want to learn" to "I want to learn" and "I will learn", so as to comprehensively improve personal qualities to adapt to the needs of future society and competition.

\section{References}

[1] Shi Xiaoyan, Zhang Jinhong. The Construction of English Autonomous Learning Mode in Higher Vocational Colleges Based on Micro-Class[J].Campus English,2016(21).

[2] He Hui. Discussion on the Ways of Cultivating English Autonomous Learning Ability of Higher Vocational Students from the Perspective of Micro-era[J].Asia-Pacific Education,2015(9).

[3] Wen Qiufang. Application of Output Drive Hypothesis in College English Teaching: Thinking and Suggestions [J]. Foreign Languages, 2013, (6).

[4] Xu Jinfen, Peng Renzhong, Wu Weiping. Investigation and Analysis of Non-English Majors' Autonomous English Learning Ability [J]. Foreign Language Teaching and Research, 2004, (1).

[5] Xu Jinfen, Li Weizhen. The Influence of Learners' Controllable Factors on College Students' English Self-learning Ability [J]. Modern Foreign Languages, 2014, (5). 